\title{
Estudio piloto de aislamiento y fenotipificación de bacterias que participan en los procesos de biolixiviación, en las zonas mineras del Departamento de Boyaca
}

\author{
Lucia Constanza Corrales', Ligia Consuelo Sánchez¹, Paula Sánchez Cortes', Alba Sánchez León', Viviana Sánchez \\ Quintero', Julieth Zárate Díaz'1. \\ Programa de Bacteriología y Laboratorio Clínico, Facultad Ciencias de la Salud, Universidad Colegio Mayor de Cundinamarca. \\ Correspondencia: Icorralesr@unicolmayor.edu.co \\ Recibido: 24-02-2006 / Aceptado:10-05-2006
}

\begin{abstract}
Resumen
Una alternativa para disminuir la contaminación ambiental generada por el empleo de sustancias químicas cuando se extraen metales pesados en la industria minera, así como los costos en materiales químicos es utilizar en este proceso microorganismos que han demostrado realizar esta actividad, denominados biolixiviadores. Para ello es necesario identificar y fenotipificar estos microorganismos. El objetivo de este proyecto fue aislar y fenotipificar microorganismos biolixiviadores obtenidos de cuatro minas de esmeraldas del departamento de Boyacá (Muzo, Coscuez, Chivor y Consorcio). El muestreo se realizó en agua y roca, habitat principal de las bacterias que participan en los procesos de biolixiviación. El aislamiento se realizó previa preparación de cada una de las muestras, las cuales se sembraron en el medio de cultivo 9K, líquido y sólido, e incubaron por siete días a $37^{\circ} \mathrm{C}$. Se evidenciaron cambios físicos en la intensidad de color y en el aspecto en los medios de cultivo, lo que permite presumir que ha ocurrido alguna acción de las bacterias lixiviantes sobre los compuestos del medio. La observación microscópica evidenció la presencia de bacilos gram negativos y cristales. Por otra parte, se confirmó la característica de ser bacterias acidófilas ya que su desarrollo se obtuvo a $\mathrm{pH}$ entre 1 y 2,5 . Los resultados obtenidos en este estudio permitieron concluir que en estas minas hay presencia de organismos bacterianos con morfología y comportamiento bioquímico compatible con bacterias biolixiviantes del género Thiobacillus. El aislamiento y fenotipificación obtenidos in vitro abre la posibilidad de establecer un método óptimo para su conservación y posterior utilización en procesos de bioremediación.
\end{abstract}

Palabras clave: Biolixiviación, Thiobacillus s.p., bacterias acidófilas, fenotipificación.

\begin{abstract}
An alternative to diminish the environmental contamination generated by the use of chemical substances when heavy metals in the mining industry as well as the costs in chemical equipments are extracted is to use in this process microorganisms that have demonstrated this activity, denominated bioleaching. For this, is necessary to identify and to phenotyping these microorganisms. The objective of this project was to isolate and to phenotype obtained bioleaching microorganisms of four emerald mines of the department of Boyacá (Muzo, Coscuez, Chivor and Consorcio). The sampling was made in water and rock, main habitat of the
\end{abstract}


bacteria that participate in the Bioleaching processes. The isolation was made previous preparation of each one of the samples, which seeded in culture means 9K, liquid and solid, and incubated by seven days to $37^{\circ} \mathrm{C}$. showing physical changes in the color intensity and the aspect in culture means, which allows to be conceited that it has happened some action of the leaching bacteria on compounds of means. The microscopic observation demonstrated the presence of gram negative bacilli and crystals. On the other hand, the characteristic of being was confirmed acidophilic bacteria since its development was obtained to $\mathrm{pH}$ between 1 and 2,5. The results obtained in this study allowed to conclude that in these mines there is presence of bacterial organisms with morphology and compatible biochemical behavior with biolixiviantes bacteria of the Thiobacillus sort. The obtained isolation and fenotipificación in vitro open the possibility of establishing an optimal method for its conservation and later use in bioremediation processes.

Key words : Bioleaching, Thiobacillus s.p., acidophilic bacteria, phenotipying

\section{Introducción}

En la industria minera se hace frecuente la búsqueda de métodos menos contaminantes en la extracción de metales, ya que se ha visto que los métodos convencionales generan altos costos en lo económico y ambiental, debido a la utilización de procesos químicos que producen alto índice de contaminación.

Una alternativa biológica a este problema es la utilización de microorganismos biolixiviadores, los cuales se encuentran presentes en los micro ambientes ricos en metales, convirtiéndose en una buena opción para su lixiviación.

El valor agregado que genera la utilización de esta alternativa biológica se representa en mejorar la calidad de vida de los mineros y del ecosistema que rodea esta industria. En Colombia existen algunos estudios preliminares que demuestran la presencia de microorganismos nativos, capaces de realizar procesos de bioloxiviación (1).

La Lixiviación Bacteriana, también conocida como Biolixiviación o Biooxidación de Sulfuros, puede ser definida como un proceso natural de disolución que resulta de la acción de un grupo de bacterias especificas para lixiviar, o extraer, metales o concentrados minerales presentes en las minas. El producto final de la biolixiviación es una solución ácida que contiene el metal en su forma soluble (1).
Estas bacterias mineras que tienen la propiedad de hacer solubles algunos minerales, reemplazan los procesos químicos y disminuyen la cantidad de residuos contaminantes. Una de las bacterias más estudiadas y reportadas es Thiobacillus de la cual se supone posee dos sitios de transferencia de electrones, uno para la oxidación del azufre y otro para hierro localizados en la membrana celular (2). El sistema de oxidación de hierro (II) en T. ferrooxidans está relacionado con la membrana celular. La enzima ferrooxidante clave parece ser la citocromo c-Fe ${ }^{+2}$ oxidoreductasa; en el proceso también intervienen la coenzima Q y el citocromo a, quienes realizan el transporte de electrones. Existe una proteína de cobre, que serviría como el aceptor inicial de electrones de la oxidación de Fe(II): Rusticianina, la que es fácilmente reducida por $\mathrm{Fe}(\mathrm{II})$ (3), y de ella depende que la bacteria reduzca el sulfato por asimilación, él cual despolariza su membrana para permitir al ión ferroso enlazar a sitios de transporte de la proteína y funciona como ligando para la síntesis de complejos susceptibles de oxidación a pH menor de 3.5 (2).

Una de las explotaciones mineras más importantes a nivel económico en Colombia es la de esmeraldas. Desde 1916, se han realizado estudios sobre la composición litológica de las minas de Muzo y se estableció la composición de pirita en estas. Medina en 
1970 concluye que todos los elementos necesarios para la formación de esmeraldas están originalmente en las lutitas negras, y que se formaron mediante soluciones descendentes (hidrotermales de origen nomagmático) que condujeron a la lixiviación de los elementos de las pizarras carbonosas que finalmente, formaron las esmeraldas.

En 1972, Beus \& Mineev (4) analizaron la distribución geoquímica de los elementos en la zona tectónica e indicaron fuerte lixiviación de $\mathrm{K}, \mathrm{V}, \mathrm{Th}$, $\mathrm{U}, \mathrm{Y}, \mathrm{Mo}, \mathrm{Sn}, \mathrm{Pb}, \mathrm{Zn}, \mathrm{Cs}, \mathrm{Cr}, \mathrm{REE}$ (elementos de las tierras raras) y concentración por alteración metasomática de $\mathrm{Na}, \mathrm{Mn}, \mathrm{Mg}, \mathrm{CO}_{2}$ y $\mathrm{S}$ en lutitas negras y venas, y la presencia de berilio proveniente de las soluciones profundas.

Se puede observar que estos estudios se han centrado en la composición litológica de estas zonas y en la formación de las esmeraldas. Sin embargo, los procesos de lixiviación a los que se refieren son explicados por factores abióticos. El presente trabajo busca demostrar que existen microorganismos quimiolitotró-ficos, que por su capacidad de oxidar el ión ferroso, pueden ser empleados para la concentración y extracción de elementos metálicos presentes en los compuestos sulfurados y hacen parte del factor biótico en la lixiviación. Este estudio permitió el aislamiento e identificación microscópica de bacterias lixiviadoras de hierro, presumiblemente del género Thiobacillus por su capacidad de crecimiento in vitro en medios de cultivo con $\mathrm{pH}$ ácido y sales metálicas como sustrato, las cuales fueron obtenidas de muestras de agua y roca (pirita y lutitas negras) de las minas de esmeraldas de Muzo, Coscuez, Chivor y Consorcio en el departamento de Boyacá.

\section{Materiales y métodos}

La presente investigación desarrolla un diseño metodológico no experimental, prospectivo y descriptivo en la que el objetivo es observar, describir y documentar aspectos esenciales de las bacterias lixiviadoras y sus medios de cultivo. Se utilizo un muestreo no probabilistico por conveniencia.
La metodología utilizada para el proyecto se desarrollo en diferentes etapas: toma de muestras, análisis y resultados del estudio a partir de las mismas.

\section{Toma y transporte de las muestras}

La toma de muestras se realizó en 4 minas del departamento de Boyacá (Muzo, Coscuez, Chivor y Consorcio) tomando 1 muestra en cada mina de agua de drenaje y de roca, en frascos de vidrio estériles.

El transporte de las muestras se realizó a temperatura ambiente $\left(20-45^{\circ} \mathrm{C}\right)$. El análisis se desarrollo en el laboratorio de microbiología de la Universidad Colegio Mayor de Cundinamarca.

\section{Procedimiento en el laboratorio}

\section{Medios de cultivo y soluciones}

El medio seleccionado para el estudio fue el medio 9K de Silverman y Lundgren por cuanto la literatura lo describe como el adecuado para el crecimiento de este tipo de bacterias (5)(6) Para la preparación del medio 9k líquido se utilizaron: $0.025 \mathrm{~g}\left(\mathrm{NH}_{4}\right)_{2} \mathrm{SO}_{4}, 0.01 \mathrm{~g} \mathrm{de}$ $\mathrm{K}_{2} \mathrm{HPO}_{4}, 9 \mathrm{~g} \mathrm{FeSO}_{4}$ 7. H2O, 0.025g MgSO 4 7. H2O. Se disolvieron los sólidos en $250 \mathrm{ml}$ de agua destilada a pH final de 1.5, ajustado con $\mathrm{H}_{2} \mathrm{SO}_{4} 10 \mathrm{~N}$ y se esterilizó por autoclavado a 121 libras de presión por 15 minutos.

En la preparación del medio 9K sólido (5- 6) se generaron dos soluciones. La solución A: $1.75 \mathrm{~g}\left(\mathrm{NH}_{4}\right)_{2}$ $\mathrm{SO}_{4}, 0.029 \mathrm{~g} \mathrm{~K}_{2} \mathrm{HPO}_{4}, 0.058 \mathrm{~g} \mathrm{KCl}, 0.029 \mathrm{~g} \mathrm{MgSO}_{4}$ $\mathrm{H} 2 \mathrm{O}, 0.0084 \mathrm{~g} \mathrm{Ca}\left(\mathrm{NO}_{3}\right)_{2}$, la cual fue disuelta en $210 \mathrm{ml}$ de agua destilada ajustada a $\mathrm{pH} 1.9$ con $\mathrm{H}_{2} \mathrm{SO}_{4} 10 \mathrm{~N} \mathrm{y}$ esterilizada por autoclavado a 121 libras de presión por 15 minutos, y la solución B: 37.3 g de $\mathrm{FeSO}_{4} 7 . \mathrm{H}_{2} \mathrm{O}$ en $290 \mathrm{ml}$ de agua destilada a pH 1.9 con $\mathrm{H}_{2} \mathrm{SO}_{4} 10 \mathrm{~N}$, más $12 \mathrm{gr}$ de agarosa. No se esterilizó por autoclavado para evitar precipitación de compuestos y desnaturalización de la agarosa.

Una vez esterilizada la solución A, se filtró y mezcló con la solución B y se llevo a ebullir. Posteriormente se sirvió en cajas de Petrie $15 \mathrm{ml}$ de medio, se enfriaron y refrigeraron. Cada uno de los lotes de 
medio preparado se sometió a control de esterilidad a $37^{\circ} \mathrm{C}$ por 48 horas, en aerobiosis.

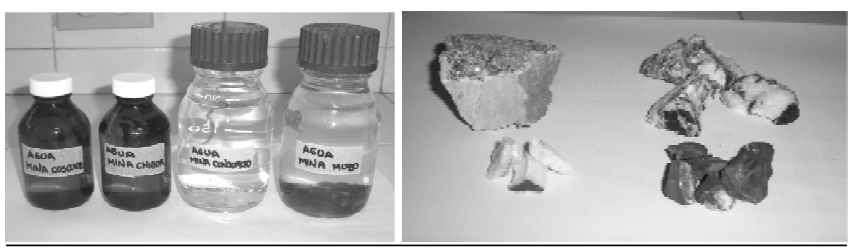

Figura 1. Muestras de agua y rocas de las 4 minas.

\section{Preparación y siembra de las muestras}

Las muestras permanecieron en reposo a temperatura ambiente para facilitar que las bacterias ferruginosas y sulfuradas estuvieran presentes.

Las muestras de roca fueron sometidas a maceración en mortero con el fin de liberar las bacterias que pudiesen estar en las muestras.

\section{Homogenización de las muestras}

Se tomaron $30 \mathrm{~g}$ de roca macerada y $100 \mathrm{ml}$ de agua de mina en recipientes estériles independientes con $120 \mathrm{ml}$ de medio 9K líquido, y se homogenizó con agitador de Mazzini por 30 minutos.

\section{Filtrado}

Las muestras homogenizadas se sometieron a un primer filtrado utilizando papel Whatman No. 42 y a un segundo filtrado con filtros de membrana.

Posteriormente, las membranas se lavaron con $5 \mathrm{ml}$ de agua acida ( $\mathrm{pH} 2.0)$ y esta agua de lavado se sembró en $75 \mathrm{ml}$ de medio $9 \mathrm{~K}$ liquido en fiolas de $100 \mathrm{ml}$. Por ultimo se incubo a $37^{\circ} \mathrm{C}$ durante 7 días.

\section{Verificación de pH}

Durante el proceso de incubación se realizó control de $\mathrm{pH}$ mediante indicador universal en papel con el fin de verificar que el $\mathrm{pH}$ se mantuviera entre $1,0 \mathrm{y}$ 2,0, ideal para el crecimiento de bacterias acidófilas.

\section{Verificación del crecimiento bacteriano}

Luego de siete días de incubación, se realizó coloración de Gram en cada uno de los cultivos para verificar la presencia de las bacterias.
Se realizó resiembra de las muestras incubadas (1.5 cultivo preincubado en $4 \mathrm{ml}$ de medio líquido $9 \mathrm{k}$ en tubos de $13 \times 100$ ) previa homogenización por agitación. Se utilizó como control un blanco (medio sin inocular) para tener un indicador macroscópico de color y controlar las posibles reacciones químicas que pueden suceder con los compuestos del medio.

La incubación de esta fase se realizó por siete días para permitir una mayor concentración de bacterias y facilitar su aislamiento.

\section{Aislamiento de las bacterias en medio sólido}

A los siete días de incubación de los cultivos en tubo, se sembraron en placas de medio $9 \mathrm{~K}$ sólido a partir de cada uno con asa calibrada de $10 \mu 1$ y metodología por estría sencilla, previa homogenización por mezcla con vortex.

Se incubaron a $37^{\circ} \mathrm{C}$ por siete (7) días en atmósfera de $5 \%$ de $\mathrm{CO}_{2}$.

De las colonias obtenidas en el medio sólido se realizó coloración de Gram y aislamiento de nuevo en medio 9K sólido, se incubo por siete días en las mismas condiciones, realizando coloración de Gram pasado este tiempo.

Todos los medios líquidos se incubaron en total por ocho semanas hasta cuando se finalizó el experimento.

\section{Resultados}

El ensayo permitió verificar la presencia de bacterias con morfología bacilar con afinidad Gram negativa, carácter acidófilo por su desarrollo en medios con $\mathrm{pH}$ entre 1,0 y 2,0 . y ser quimiolitótrofas (7) por el crecimiento y sostenimiento en el tiempo a expensas de compuestos inorgánicos en las muestras de las minas de Consorcio y Coscuez. Las muestras provenientes de las minas de Chivor y Muzo no evidenciaron formas bacterianas mediante la coloración con Gram.

www.unicolmayor.edu.co 


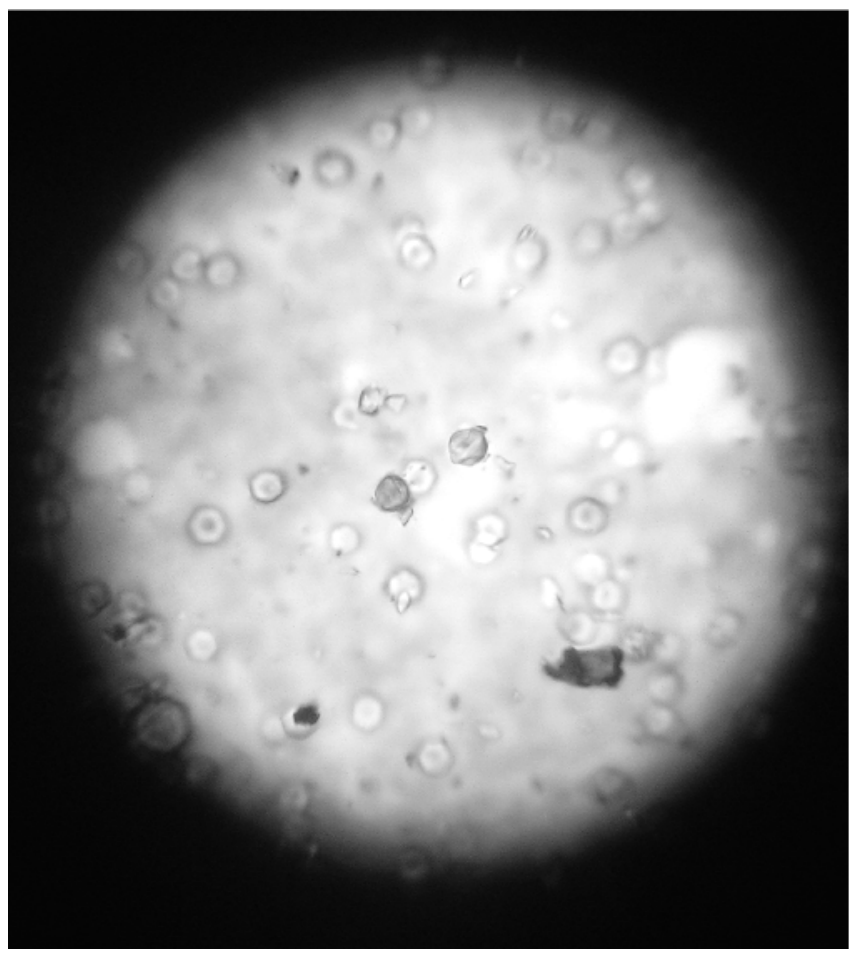

Figura 2. Agua de la mina Coscuez, se observan bacilos Gram negativos, aumento de 100x y cristales alrededor de estos formando satelitismo.

Aunque se evidenció la presencia de bacterias en las preparaciones coloreadas con Gram, el número de las mismas no fue muy alto. Algunas de las razones que podrían explicar este bajo desarrollo son: que la temperatura utilizada en la incubación no corresponde a la temperatura óptima en su hábitat de origen la cual oscila entre 40 y $50^{\circ} \mathrm{C}(8)$, la provisión de oxígeno y $\mathrm{CO}_{2}$ pueden no ser las adecuadas ya que en las muestras sólidas no se proveen altas concentraciones de oxígeno y la mayoría del experimento se hizo en condiciones aerobias y se ha reportado mejor comportamiento utilizando $2 \%$ de atmósfera de $\mathrm{CO}_{2}(8-9)$.

Con relación a las sustancias provistas en los medios $9 \mathrm{~K}$, se esperó proporcionar compuestos con azufre que permitieran su sostenimiento, desarrollo y además obtener indicios de las biotransformaciones realizadas por ellas, oxidando el sulfuro a sulfito y el sulfito a sulfato (10) lo cual se evidenció mediante el cambio de color de verde traslucido a amarillo turbio en los medios líquidos utilizando el blanco como control.

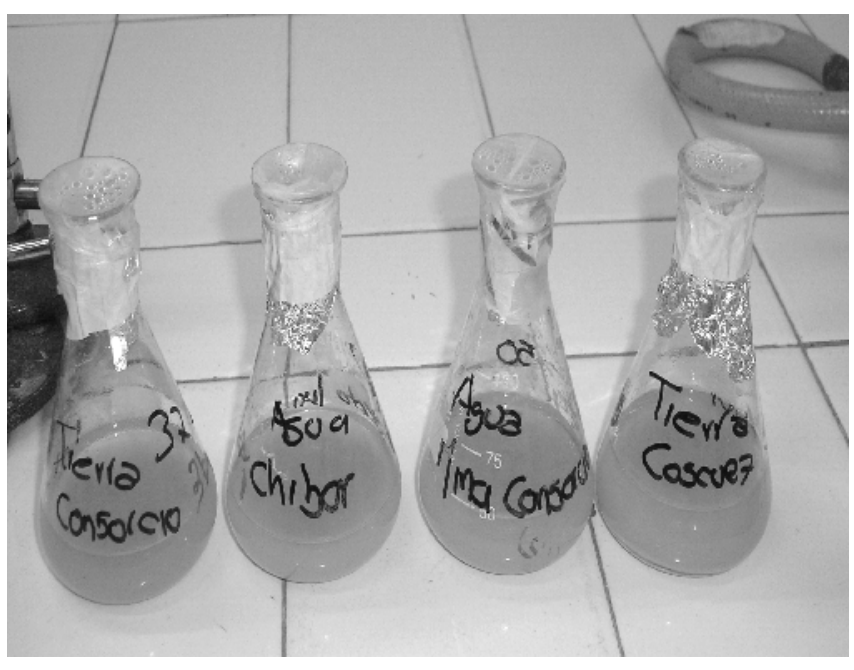

Figura 3. Medios 9K líquido primarios después de incubación

En todas las preparaciones coloreadas con Gram se observaron cristales hexagonales al parecer provenientes de las sales de azufre que componen el medio. En las figuras 4 y 5 se observan bacilos y cristales y en la figura 6 se presentan las características en cultivo de los aislamientos.

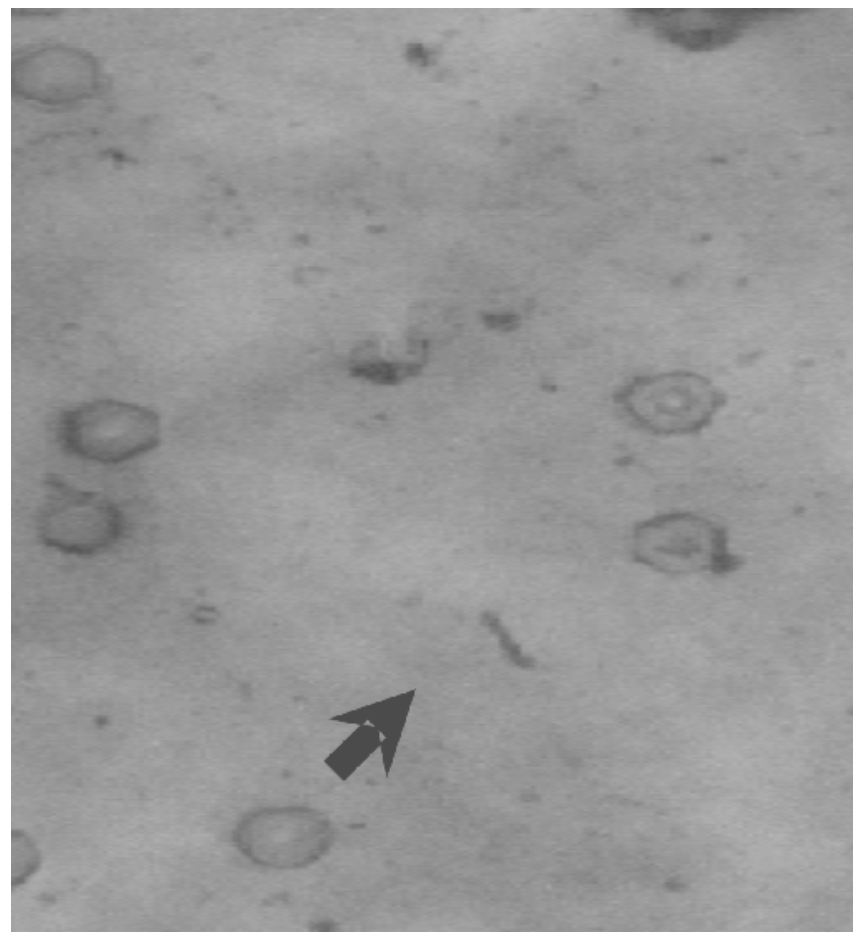

Figura 4. Coloración de Gram, se muestran bacilos y cristales. 


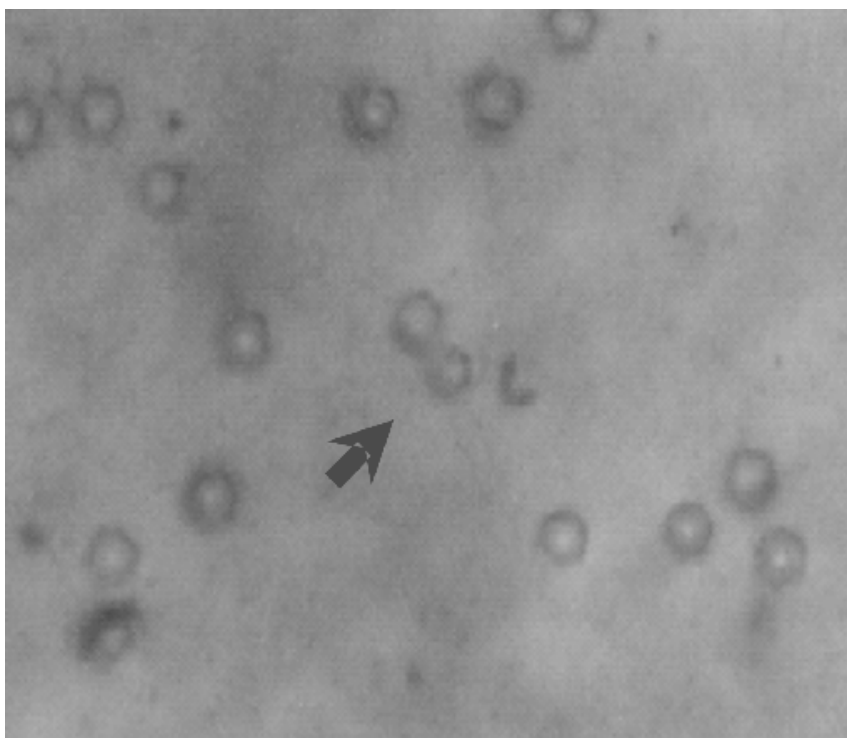

Figura 5. La presencia de cristales se evidenció en las muestras de todas las minas, se señalan las características macroscópicas del cultivo en el medio sólido $9 \mathrm{~K}$.

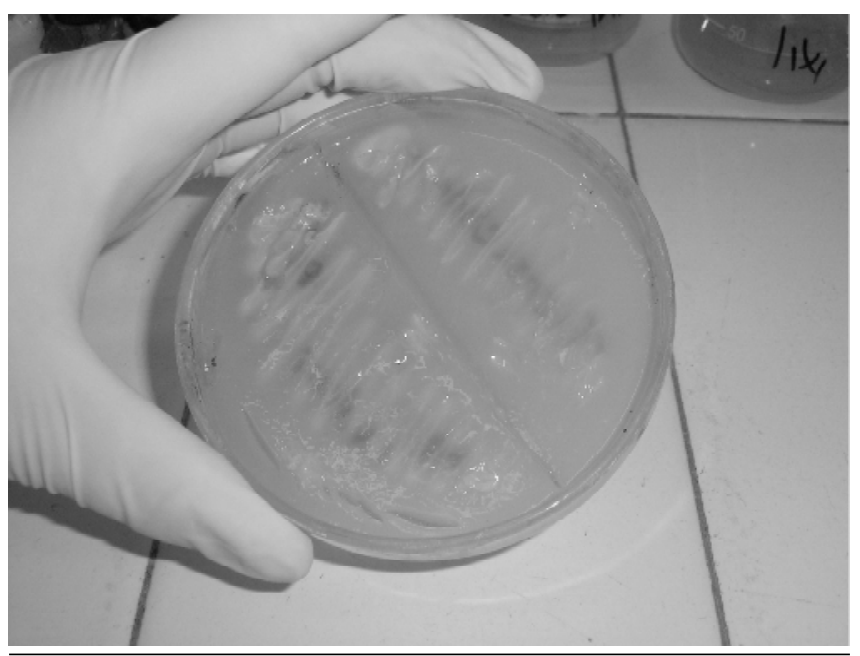

Figura 6. Medio 9K sólido, colonias amarillas, medianas, húmedas e incrustadas.

\section{Discusión}

Resultados obtenidos en experimentos previos demuestran que los microorganismos que participan en la Biolixiviación poseen características especiales de crecimiento y supervivencia tales como su capacidad de crecer a $\mathrm{pH}$ ácido (1-3 ideal 2.5) (7, 11), a temperaturas entre 2 a $37^{\circ} \mathrm{C}$ (mesofilos), a temperaturas mayores entre $45-50^{\circ} \mathrm{C}$ (termofilos moderados) llegando hasta temperaturas de $70^{\circ} \mathrm{C}$ (termofilos extremos)(8). En este experimento, solo se facilitó el crecimiento de bacterias mesófilas y se descartó la posibilidad de desarrollo de bacterias termófilas moderadas que de acuerdo con la revisión bibliográfica a ella pertenecen una gran población del género Thiobacillus.

Aunque se evidenció la presencia de bacterias en las preparaciones coloreadas con Gram, el número de las mismas no fue muy alto. Algunas de las razones que podrían explicar este bajo desarrollo son: que la temperatura utilizada en la incubación no corresponde a la temperatura óptima en su hábitat de origen la cual se ha reportado entre 40 y $50^{\circ} \mathrm{C}(8)$, la provisión de oxígeno y $\mathrm{CO}_{2}$ pueden no ser las adecuadas ya que en las muestras sólidas no se proveen altas concentraciones de oxígeno y la mayoría del experimento se realizó en condiciones aerobias y se ha reportado mejor comportamiento al utilizado $2 \%$ de atmósfera de $\mathrm{CO}_{2}(8-9)$.

Las especies bacterianas biolixiviadoras se presentan como bacilos pleomorficos Gram negativos, aunque se ha descrito que algunos termofilos muestran tinción Gram positiva como el Sulfobacillus thermosulfidooxidans. Su fuente de energía es el $\mathrm{CO}_{2}$, son aerobios estrictos y quimiolitoautotróficas ya que utilizan la oxidación de compuestos inorgánicos para generar todos los componentes de la célula, esta capacidad metabólica es la que se aprovecha para solubilizar cobre y otros minerales (7). Dichas características se constituyen en la base fundamental para el crecimiento y la conservación de los mismos.

En estudios anteriores se lograron establecer las condiciones propicias para el óptimo crecimiento de estos microorganismos, entre las que se destaca la siembra en medio de cultivo 9K de Yates y Colmes (6), al ser aisladas y al estudiar sus características metabólicas a profundidad, podrán ser utilizadas para la extracción de metales a gran escala. Sin embargo, se resalta que la Biolixiviación es un proceso lento que puede necesitar desde días hasta años dependiendo del material y método empleado.

El crecimiento típico de las colonias, no se alcanza a visualizar antes de 90 días de incubación como se 
expresa en el articulo titulado "Biolixiviación de minerales sulfurosos". Los cultivos realizados en este estudio llegaron hasta un tiempo de 35 días de incubación, tiempo que permitió visualizar el desarro1lo, fue una limitante para el crecimiento bacteriano masivo.

De acuerdo a los resultados obtenidos en este estudio se pudo concluir que de las minas Coscuez y Consorcio en el departamento de Boyacá se aislaron formas bacterianas con morfología y comportamiento bioquimico compatible con microorganismos biolixiviantes.

Para llegar a una identificación completa de los microorganismos aislados se sugiere continuar con su caracterización molecular para comprobar con certeza que son microorganismos pertenecientes a los géneros Thiobacillus s.p, Sulfobacillus s.p. o Leptospirillum s.p., entre otros.

www.unicolmayor.edu.co

\section{Referencias}

1. Agudelo J, Betancur U, Largo M. Biolixiviación de minerales sulfurosos. Revista Facultad de Ingeniería. Universidad de Antioquia. 2002; 27.

2. Boon M, Heijnen J. Chemical oxidation kinetics of pyrite in bioleaching processes. Hydrometallurgy 1998; 48:27-41

3. Guerrero R. Recuperación de valores metálicos por vía biohidrometalurgica. Universidad Nacional del Centro del Perú, Huancayo. 1990 Nov.

4. Maya M, Buenaventura J, Salinas R. Estado del conocimiento de la explotación de esmeraldas en Colombia. Ministerio de Minas y Energía. Instituto Colombiano de Geología y Minería. 2004. 90p.

5. Barron L. Growth and maintenance of Thiobacillus ferrooxidans cells. Applied and environmental microbiology. 1990. p. 2801-2806.

6. Yates J, Colmes D. Two families of repeated DNA sequences in Thiobacillus ferrooxidans. J Bacteriol. 1987; 169(5): 1861-1870.

7. Suzuki I, Lee D, Mackay B, Harahuc L, Key Oh J. Effect of Various Ions, $\mathrm{pH}$, and Osmotic Pressure on Oxidation of Elemental Sulfur by Thiobacillus thiooxidans. Applied and environmental microbiology. 1999: 5163-5168.

8. Dopson M. Potencial role of Thiobacillus caldus in arsenopyrite bioleaching. Applied and environmental microbiology. 1999: 36-40.

9. Okibe N, Gericke M, Hallberg K, Barrie D. Enumeration and Characterization of Acidophilic Microorganisms Isolated from a Pilot Plant Stirred-Tank Bioleaching Operation. Applied and environmental microbiology. 2003:1936-1943.

10. Zagury G, Narasiah K, Tyagi R Adaptation of indigenous Ironoxidizing bacteria for bioleaching of heavy metals in contaminated soils. Environ.Tech. 1994. 15: 517-530.

11. Varela P, Levica G, Rivera F, Jerez C. An Immunological Strategy To Monitor In Situ the Phosphate Starvation State in Thiobacillus ferrooxidans. Applied and environmental microbiology.1998: 4990 - 4993. 